\title{
Service Quality: A Key Determinant of Organisational Competitiveness
}

\author{
Munodawafa Njovo \\ Midlands State University, Zimbabwe \\ Caroliny Makacha \\ Midlands State University, Zimbabwe
}

\begin{abstract}
The study attempts to establish the link between service quality and competitiveness. Organisations have largely been focusing on making attempts to satisfy customer by focusing on pricing and distribution strategies. Service quality has often been neglected and this has often resulted in depressed organisational performance. A pre-dominantly descriptive research design was used. Questionnaires were distributed among respondents in organisations that are in the ICT service and distribution business. The respondents comprised of employees and customers of the said organisations. A sample size of 44 was used. It was concluded that service quality was instrumental in facilitating multiple advantages which put companies in good stead to fight competition.
\end{abstract}

Keywords: Service quality, competitiveness, competition

\section{INTRODUCTION}

In today's business environment, competition has become intense. Organisations are working tirelessly to survive in the highly competitive environment. Consumers now have a wide choice of what they want. Strategies seen as powerful in fighting competition are invented, copied by competitors and become a routine. Service quality has become an important tool in today's global competitive environment.

The ICT sector is characterised by high competition. This is probably attributable to low entry barriers and products and services that seem to be undifferentiated. According to Scofield and Katics, (2006) to a greater extent, the success of organisations is now dependant on how well customer needs have been considered in the designing and delivery of a service and the overall service quality in delivering customer satisfaction.

Key customers and employees are being lost. The extreme cases have witnessed movements of customers and employees within the industry. This often leaves the customer confused.

Customer complaints have been on the rise. Having long standing relationships with customers leads to high returns to the service provider as the connection between the two evolves through stable and less time demanding service encounter, Shoemaker and Lewis, cited in Scofield and Katics (2006). 


\section{LITERATURE REVIEW}

Recently service quality has been a powerful tool in fighting competition. Competition has been intense due to the emergence of new rivals in every sector of the economy. Fighting competition through prices is not an enough strategy based on the fact that these can be easily imitated, me too products produced and prices playing a role in fighting competition in such a scenario. Some organisations have added service quality as a strategy to withstand the pressure exerted by competitors.

Service can be defined in a number of ways depending on the context on which the word is used. Agbor (2011) defines a service as an intangible offer by one party to another at a fee for enjoying. Some authors however leave out the point of providing it at a cost. Kotler and Keller (2009) define it as an intangible performance that one party offers to another without resulting in tangible possession of something.

Quality is one of the things that consumers prioritize, and service happens to be one, Solomon (2009). Kotler cited in Agbor (2011) defines quality as the entirety of features and attributes of a product or service that gives it the ability to satisfy the declared or implied needs. Quality is also related to the value an offer has, which could bring to mind contentment or dissatisfaction on the part of the customer or consumer, Agbor (2011). Quality is also defined by Gavin cited in Ograjensek (2008) as suitability for use or as conforming to requirements at an acceptable cost (internal focus) or to performance at an acceptable price (external focus).

However, the point of defining quality as fitness for use can in other ways can be said to be subjective not objective. This is also supported by Ogranjesek (2008) who argues that fitness for use for the same product may mean different things, depending on what one wants to use the product for.

Parasuraman's definition cited in Keng (2010) defines service quality as the evaluation obtained from comparing how one organisation performs in relation with the general expectations customers have of how other firms in that industry should perform. If customers expect a speedier service delivery, failure to provide a service at an expected time by an organisation makes the quality of service provided questionable to customers. Bitner, Booms and Mohr cited in Fan and Lian (2009) define service quality as consumers' overall feeling of how substandard or superior an organisation is and its services. Cronin and Taylor's definition in Fan et al (2009) view service quality as a form of attitude customers have representing a long run overall assessment. These definitions of service quality seem to add to the view that the service quality is consumers' overall judgement of the quality of service a company provides.

The above definitions however eliminated the subjectivity factor of service quality which is considered useful in the study of service quality. This is supported by Bruhn and Georgi (2006) who state that service quality is not objective but subjective for each customer. Parasuraman cited in Yadav et al (2013) adds on to say that service quality is the extent at which a service meet up or surpass customer's expectations or the gap that exist between consumers perceptions and expectations.

Ziethaml and Rust's definitions of service quality, cited in Prakash (2010) add on to classify service quality as customer's opinion of how excellent a service is and involves assessment of the three dimensions of service quality encounter namely, process quality, service environment, technical quality and represents the total perception a customer has concerning the service received. This has also appeared in Roest and Pieters' definition cited in the same 
source that service quality is a comparative and cognitive variation between what customers have once experienced and performances concerning service benefits. This shows that for consumers to regard a service as of high quality a lot of factors are brought forward. Since services are intangible, the tangibility factor of the service provided by an organisation is important to customers, for example, customers may look at the organizational premises, the furniture whether its up to standard with the promised service.

Service quality in management and marketing's view is the degree to which customers' perceptions of service meet up and/or go beyond their expectations, Agbor (2011). Parasuraman's research findings cited in Agbor (2011) are of the view that measuring service quality as the difference between perceived and expected service is a valid way and can help management identify the existing gaps in the services they offer. Sedlacek et al (2011) declare that a service is of high quality if it meets or surpasses customer's expectations.

Bruhn and Georgi( 2006 ) postulate that service quality is subjective. Before customers receive a service they have the type of service they want to be given in their minds. Once a service is provided to them they tend to rate the service they have received (perceived operation of the service) to what they had expected to receive so as to obtain an answer of saying whether the company has a high service quality or not. They are of the view that the difference between the two provides what is known as the service quality gap. Perceived quality is defined by Keng (2010) as the overall judgment of how superior a service is. Ziethaml, Valarie and Bitner (2006) add on to define it as a subjective judgment of actual service experience. Experience is the real quality of service a customer receives from the service provider. The above definitions are all in support of subjectivity in service quality which is a key element in this subject.

Kadier and Masinaei (2011) define perceived quality as difference between customer expectation and satisfaction. They further asset that a positive answer to the equation shows some level of satisfaction, where as a negative answer shows that there is a gap in service quality. In other words a gap symbolizes dissatisfaction. This has also been supported by Lovelock and Wirtz (2011) who postulate that as long as service performance or experience meets customers' expectations, they become satisfied and if the opposite happens, complaints, switching to competitors may be experienced from customers. Excellent service quality seems to be a pre-requirement to satisfying customers and creating customer loyalty.

Based on the service quality equation, this means that the service quality gap differs depending on the customer. Customer's perceptions concerning a service are not the same hence the service quality gap. Backing up this, other research studies refer to service quality as an intangible and indescribable construct because of the unique characteristics of services which are inseparability, heterogeneity, intangibility, perishability, and due to these characteristics, it is often measured by customers' perceptions regarding the services of a company, Prentice (2012). Chand and Anaraud (2008), add on to say that knowing a customer's perception of the service delivered can help measure the service quality of a company.

Parasuraman's comment on service quality cited in Ganguli and Roy (2010) stipulates that above and beyond service results, service quality perceptions also entail assessment of the service delivery procedure. Lehtinen and Lehtinen also cited in Ganguli and Roy (2010) add on to say that the conceptualization of service quality have to include both the procedures as well as the service outcomes. This has also been supported by Yoo and Park (2007) who say that a firm's capacity to serve the customer needs as well as to preserve its competitive advantage also has effect on how customers perceive the quality of service the firm offers. Therefore 
service quality has been an important area of study and concern in today's organisations which want to withstand the great competition pressure in the business world.

Basing on the past performances, customers can have different perceptions concerning the quality of service received. In addition to that, in service provision, first impression plays a critical role in building the level of perception of customers. There is no second opportunity for first impression. Organisations therefore have to do their best in raising and maintaining their service quality standards because they have a bearing in how customers perceive their quality of service.

Service quality has been viewed as a multi-dimensional concept. This is supported by Bruhn and Georgi( 2006 ) who state that the characteristics of service quality are not objective but personal for each customer. They add on to say that this is because a service itself is for the most part a process, and the key factor here being that services are intangible.

Gronroos cited in Stromgren (2007) identified service quality as having two dimensions, the functional aspect and technical aspect. The functional aspect covers "how" a service is provided where as the technical aspect covers "what" service is provided. Kubicki (2011) states that service quality can be demonstrated in terms of usability (ease of understanding), safety (information protection), performance (effectiveness), business stability (appropriateness of service for conducting activities), regulatory and interoperability (ability of a service to interoperate with other services) and stability (ability of the service to be available). Bruhn and Georgi (2006) add on to say that service quality can be demonstrated through up to date material, usability of equipment, appealing physical facilities, organized equipment and well dressed employees. Lihtinen cited in in Stromgren (2007) views service quality in terms of physical quality, corporate (image) quality and interactive quality.

In his analysis, physical quality are the tangible aspects of a service where as the corporate quality refers the public and customers' (potential and current) view of the image of the service provider.

The above views of authors however do not mention the ambient part of service quality which is also an important factor to note in service quality. This factor has been brought to light by Brandy and Cronin's descriptions of service quality cited in Stromgren (2007), which state that service quality comprise of ambient conditions, social factors and facility designs. Their definition encompasses service environment as the elements of the service delivery process. This has also been supported by Wirtz and Lovelock (2011) who state that the service environment and its accompanying atmosphere have an effect on customers' behavior through heightening their interest for certain services or occurrences.

However what is regarded as a quality service differs, depending on the customer. As once said by Parasuraman, there is no general agreement on the content and nature of quality. Service quality factors are not uniform as they are judged subjectively. Edvardsson, cited in Chang and Annaraud (2008) adds on to say that the concept of service should be dealt from the customer's point of view, based on the opinion that a service can mean different things to customers, that is, is difficult to define or measure since it is an experience.

This is also supported by Kotler (2003) who argues that services are difficult to evaluate, basing on the fact that their evaluation is based on experience qualities and after the purchase. Once there is a discrepancy in the perceived and expected quality of service, a service quality gap is created 
In comparison of the definitions above, the definition of service quality adopted for this study is derived from Parasuraman cited in Yadav et al (2013), Prakash (2010).Kadier and Masinaei (2011) . Service quality is the degree at which a service delivered meets or exceeds customer's perceptions or the gap that exist between what consumers perceive and expect, looking at the different service quality dimensions.

Service quality has been a topic of major interest to many researchers. A lot of studies have been carried out to identify the dimensions service quality has in order to try measure service quality. Johnston cited in Dehghan (2006) is of the view that discovery of the determinants of service quality is necessary in order to be able to identify, evaluate, control, and improve customer perceived service quality.

Agbor (2011) postulates that the aim of providing quality services is to satisfy customers and measuring service quality is a better way to read aloud whether the services are good or bad and whether the customers will or are satisfied with it. Haywood quoted in Agbor (2011) is of the view that service quality comprises of physical facilities, personal behavior and professional judgment. He stated that a balance of these three must be achieved.

However due to the intangibility characteristic of services there are more dimensions of service quality. A number of service quality models have been developed to try measure and identify the dimensions service quality has. Cronin and Taylor developed the SERVPERF model of service quality. Other models of different fields were also developed, for example, models for measuring the quality of services in libraries.

Lehtinen and Lehtinen cited in Ganguli and Roy (2010) offered a comprehensive model with three dimensions of service quality: physical, interactive and corporate.

In their view, physical quality is about the quality of material products involved in service delivery and consumption. Interactive dimension refers to the interaction between the customers and the service organization employees. Corporate quality is explained as the customer perceived corporate image.

Levesque and McDougall obtained core quality, relational quality and tangibles as dimensions of service in the retail banking sector. Caruana et al in 2000 identified assurance, consistency, and responsiveness as service quality dimensions. Burke et al also viewed the physical aspects, consistency, problem solving guiding principle, personal interaction, product quality as dimensions for service quality in retail stores, Ganguli and Roy (2010) Foodness and Murray (2007) found that customers use the dimensions of effectiveness, efficiency, productivity, de'cor, maintenance and interaction as judgments for service quality in airport services. More so, Brady and Cronin in (2001) conducted a multi industry study and concluded that service quality consists of dimensions namely, outcome (waiting time and tangibles), employee interactions and environmental quality (ambient and social conditions and facility design), Roy et al (2010)

One of the most widely used models of service quality is the SERVQUAL model. This model was developed by Parasuraman et al in 1988, Ganguli and Roy (2010). In their research, Parasuraman et al identified 5 dimensions of service quality which are, reliability, assurance, tangibility, empathy and responsiveness, Adbor (2011).

The subject of competitive advantage embrace that firms' differences in performance is as a result of that they have different assets that do not disseminate to competing firms, Powel and 
Starbuck (2010).According to Barney quoted in Arild(2013) a firm can be said to have a sustained competitive advantage when it is implementing a value creating strategy not concurrently being realized or used by any current or potential competitors and when these other firms are unable to copy the benefits of this strategy. .

However competitive advantage is gained in a number of ways not only in having a unique strategy that is simultaneously not being implemented by competitors, but it can be about finding a way that will make you perform well above the competition even though the same resource or strategy is used by the competition. This has also been supported by Porter cited in Tarabieh and Al-alak (2011) who defines competitive advantage as an benefit over competitors gained by offering more value to consumers, either by means of lower prices or by providing greater benefits and services that defend a higher price. Tarabieh et al (2011) states that in this definition Porter defined competitive advantage along the three dimensions of cost, differentiation and focus, with competitors trying to differentiate themselves from those seeming as "stuck in the middle" without competitive advantage.

Chowdhury cited in Tarribieth (2011) describes competitive advantage as the result of differentiation. This has also been supported by other researchers like Morgan cited in Mantyma (2013) who states that companies can gain competitive advantage through performing at lower costs or in a way that differentiates them from the competition and creates a greater value for customers.

A firm can distinguish itself from the competition in various ways which encompass offering innovative features, launching effective promotion, providing high quality service, developing a strong brand name, and so on, Li and Zhou (2010). Henderson cited in Terabieth (2011) argue that it would be eccentric to find an organisation that competes for competitive advantage on all the dimensions of differentiation but they should however gain competitive advantage from one or the other dimensions.

It is also indicated by Amonini et al (2010) that service firms seek to differentiate themselves in various ways like providing better service quality and greater value, developing brands with strong reputations, and developing long-term relationships in order to achieve competitive advantage, and superior. Flit, King and Ma cited in Rose et al (2010) add on to say that competitive advantage results from a number of factors, including operational efficiency, mergers, achievement, levels of diversification, form of diversification, organisational structures, composition and style of upper management, human resource management, handling of political and social influences in the market, compliance to various interpretations of socially responsible behaviours, international expansion, cross-cultural adaptation, and various other organisational and industry-level phenomena.

Rose et al (2010) came up with four empirical indicators of the potential of firm's resources to generate sustained competitive advantage which are named value, exclusivity, inimitability, and non-substitutability. Having gained competitive advantage, there is need for organisations to develop ways that will help sustain it. Once the competitive strategy or a resource of a firm can be obtained or generated by a competitor more than the initial organisation itself, the firm loses the advantage over that strategy or resource 


\section{METHODOLOGY}

Descriptive research design was used. 44 questionnaires were distributed among employees and customers of companies in the ICT business. Stratified random sampling was used to select the respondents. 40 questionnaires were returned, indicating a response rate of $90 \%$. Data was analysed by means of SPSS.

\section{DISCUSSION}

The majority of the respondents noticed that service quality was poor. Companies in the sector were not reliable, prompting customers to hop from one company to another in search of products and services. There were concerns regarding the accuracy of orders placed by customers. The order time cycles were long, an attribution that could be placed on staff incompetence. Respondents indicated that operating costs were going up and profit levels had seriously declined. Companies no longer had loyal customers as was the case in the yesteryears. A new phenomenon was being witnessed in which customers had become one time purchasers. The expectations of customers were not being met.

\section{CONCLUSION}

The purpose of this study was to examine the impact service quality has on gaining a competitive advantage for organizations, the push factor being that services can be a competitive way for businesses to perform better and differentiate itself in a way that cannot be imitated easily and exactly by the competition. Organizations had products of high quality and competitive prices. However, these were being overshadowed by poor service quality standards, such as after sales service, inaccuracy of service delivery and poor responsiveness.

Service quality is related to organizational performance. When service quality standards are high organizational performance is improved in terms of customer relations, profits, market share, corporate image, customer loyalty among other factors. According to the research findings, a decline in the service quality standards was seen to move in the same direction with a decline in performance of the organization though the same products were sold and the market was the same.

\section{References}

Agbor, J. (2011) The Relationship Between Customer Satisfaction and Service Quality, Umeå University, Sweden

Al-alak, B., Saeed, M.Z. and Tarabieh, A.,Gaining Competitive Advantage and Organizational Performance through Customer Orientation, Innovation differentiation and Market differentiation, International journal of Economics and Management Sciences vol. 1, no. 5, 2011, pp. 80-91

Bjeković, M. and Kubicki, S. Service quality description - a business perspective,Proceedings of the Federated Conference on Computer Science and Information Systems pp. 513-520,Luxembourg

Brady, M. and Cronin, J.J. (2001), Some new thoughts on conceptualizing perceived service quality: a hierarchical approach, Journal of Marketing, Vol. 65 No. 3, pp. 34-49.

Brito, C., Relationship marketing: Old wine in a new bottle , Innovative Marketing Journal, Volume 7, Issue 1, 2011

Dehghani, M.(2013), Review of the current gap between clients' expectations and perceptions of received service in national library by using gap analysis model, Performance Measurement and Metrics, Vol. 14 Iss 1 pp. 45 - 60

Gronroos, C.N. (2007) Service Management and Marketing: Customer Management in Service Competition,JohnWiley\& Sons, Ltd, Chichester

Kadir,H. Rahmani, N. and Masinaei, R., Impacts of service quality on customer satisfaction, International Journal of Trade, Economics and Finance, Vol.2, No.1, February, 2011 
Kheng, L., Mahamad, 0 and Ramayah, T., The Impact of Service Quality on Customer Loyalty , International Journal of Marketing Studies Vol. 2, No. 2; November 2010

.Majeed, S. The Impact of Competitive Advantage on OrganizationalPerformance, European Journal of Business and Management, Vol 3, No.4, 2011

Mantymaa, J. (2013) Gaining competitive advantage through quality of services in financial industry, University of Oulu, Oulu

Mitra, A. and Prakash, J. and Patankar, G., Estimation of Penalty Costs in Service Industries, Advances in Business and Management Forecasting, Volume 9, 47-57, 2013

Mohammad, A., Ahmad, M and Naser,B.,The Relationship between Internal Service Quality and Organizational Performance in Iran's Ministry of Sports and Youth. Journal of Basic and Applied Scientific Research, 2(11)1182911833, 2012

Ograjensek,I., Service quality Statistical Practice in Business and Industry,2008 John Wiley \& Sons, Ltd

Powell, C., Rahman N. and Starbuck, W. , European And North American Origins Of Competitive Advantage,The Globalization of Strategy Research Advances in Strategic Management, Volume 27, 313-351, 2010

Rose,R., Abdullah, H. and Ismad, A., A Review on the Relationship between Organizational Resources, Competitive Advantage and Performance,The Journal of International Social Research Volume 3 / 11 Spring 2010

Schofield, P. and Katics, N. , Swedish Hotel Service Quality and Loyalty Dimensions, Advances in Hospitality and Leisure, Volume 2, 123-157,2006

Tan, B., Wong, C., Lam, C., Keng, O. and Felix, C., Assessing the link between service quality dimensions and knowledge sharing: Student perspective, African Journal of Business Management Vol. 4(6), pp. 1014-1022, June 2010

Yap, S. ,Lian, F., Service Quality And Customer Satisfaction:Antecedents Of Customer's Re-Patronage Intentions,Kdu colleges Academic Journal 4

Zineldin, M., Quality and customer relationship management (CRM) as competitive strategy in the Swedish banking industry, The TQM Magazine Vol. 17 No. 4, 2005 pp. 329-344

Zeithaml, Valarie A., Mary Jo Bitner, and Dwayne D. Gremler (2010), Services Marketing Strategy, in Wiley International Encyclopedia of Marketing: Marketing Strategy, Vol. 1

Zeithaml, V.A., Bitner, M.O., and Gremler, D.E. (2009) Services Marketing: Integrating Customer Focus Acrossthe Firm,Mcgraw-Hill/Irwin, New York. 